\title{
Matching conducted EMI to international standards
}

CONFERENCE PAPER - FEBRUARY 2002

DOI: 10.1109/PSEC.2002.1023899· Source: IEEE Xplore

CITATIONS

2

6 AUTHORS, INCLUDING:

\section{F.s. Dos Reis}

Pontifícia Universidade Católica do Rio Gra.. .

54 PUBLICATIONS 224 CITATIONS

SEE PROFILE

Javier Sebastián

University of Oviedo

244 PUBLICATIONS 2,466 CITATIONS

SEE PROFILE
José Antenor Pomilio

University of Campinas

129 PUBLICATIONS 1,137 CITATIONS

SEE PROFILE

Javier Uceda

Universidad Politécnica de Madrid

221 PUBLICATIONS 3,010 CITATIONS

SEE PROFILE 


\section{Matching Conducted EMI to International Standards}

\author{
F. S. Dos Reis, J. C. M. de Lima, V. M. Canalli, \\ Pontifícia Universidade Católica do Rio Grande do Sul \\ Faculdade de Engenharia \\ Departamento de Engenharia Elétrica \\ Avenida Ipiranga, 6681 - Porto Alegre - RS \\ CEP 90619-900 - Brazil \\ e-mail:f.dosreis@ieee.org
}

\begin{abstract}
In this digest, we will present a methodology that allow us to accommodate the conducted Electromagnetic Interference (EMI) generated by power factor correctors to international standards in the design step. EMI filter design considerations and EMI predictive procedures are presented. The predictive procedures are based in a family of curves that allows us to determine the conducted Electromagnetic Interference (EMI), generated for the basic PFC converters (Boost, Buck-Boost, Zeta, Sepic, Cuk, and Buck converters). Using these curves we can determine the amplitude of the first harmonic in $\mathrm{dB} / \mu \mathrm{V}$ in accordance with the CISPR 16 standard. Therefore, with this information it can be possible to design the EMI filter.
\end{abstract}

\section{INTRODUCTION}

A crucial question in recent years has been the reduction of the product development time, because the product lifetime is becoming shorter and shorter. Keeping this in mind, it is important to minimise the EMI failures, because the legitimate cost of failing EMI compliance is not the charge made by the test facility for re-testing. Certainly this can be expensive with Test House fees of up to U\$ 1500 by day. But those fees fade into insignificance when compared with the impact of the resulting delay on product time to market [1].

To know the influence of the EMI injected into the AC line by the power converters working as Power Factor Correctors (PFC) in the electronic design is becoming more and more important. This is because today most of the loads have an input power converter. These converters needs to fulfil the international standards for EMI. Current and future regulations limit the generation of conducted and radiated noise. These regulations also limit the minimum power factor for the equipment connected to the $\mathrm{AC}$ line.

All these facts demonstrate the importance of the EMI evaluation and reduction in power converters working as PFC.

In this work will be presented some EMI filter design considerations associated with a method for determination of the conducted EMI generated by Power Factor Corrector (PFC), using the method presented by J. Uceda et al [2]. Using this two tools the reader will be able to adequate the EMI, generated for (Cuk, Buck, Boost, Buck-Boost, Sepic and Zeta converters working as PFC), in all operates modes Continuous Conduction Mode (CCM), Discontinuous Conduction Mode (DCM) and Frequency Modulation (FM), to international Standards.

The method employed to determination of conducted EMI

$\begin{array}{ccc}\text { J. A. Pomilio } & \text { J. Sebastián and } & \text { J. Uceda } \\ \text { Universidade de } & \text { Universidad de } & \text { Universidad } \\ \text { Campinas } & \text { Oviedo } & \text { Politecnica de } \\ \text { Brazil } & \text { Spain } & \text { Madrid } \\ & & \text { Spain }\end{array}$

in PFC consist in a group of curves that allow us to determine the amplitude of the conducted EMI Differential Mode (DM) (first harmonic) in $\mathrm{dB} / \mu \mathrm{V}$ in accordance with the International Special Committee on Radio Interference publication 16 (CISPR 16) [3] standard. We only present the first harmonic once that the filter design is determinated by the first harmonic [4]. The curves are made taking into account a simulation of the converter input current and the EMI measuring apparatus in accordance with CISPR 16. A very good method for this simulation was presented by Albach [4].

\section{EMI DESIGN CURVES}

In this section we present a set of curves that allow us to determine the amplitude of the conducted EMI DM (first harmonic) in $\mathrm{dB} / \mu \mathrm{V}$ in accordance with the CISPR 16 (3) standard, for the more employed PFC converters. In this paper we present the EMI design curves for the Boost (in CCM, DCM and FM modes), Buck-Boost, Zeta (in CCM, DCM and FM modes), Sepic and Cuk (in CCM, DCM and FM modes) converters.

All curves are plotted in agreement with the characteristics shown in Table I. In the y-axis, the conducted noise differential mode in $\mathrm{dB} / \mathrm{MV}$ for the switching frequency (SF) $\left(\mathrm{F}_{\mathrm{s}}\right.$ in $\mathrm{MHz}$ ) is shown. In the $\mathrm{x}$-axis we have the SF . In FM mode the $\mathrm{x}$-axis shows the minimal $\mathrm{SF}\left(\mathrm{F}_{\mathrm{s} \text { min }}\right.$ in $\left.\mathrm{MHz}\right)$.

TABLE I

CONVERTERS' PARAMETERS

\begin{tabular}{||ll||}
\hline Reference Power & $P_{\text {Ref }}=1 \mathrm{~W}$ \\
\hline Peak Reference Input Voltage & $\mathrm{V}_{\mathrm{g} \text { Ref }}=311.13 \mathrm{~V}$ \\
\hline Output Voltage & $\mathrm{V}=380$ to $880 \mathrm{~V}_{\mathrm{DC}}$ \\
\hline Switching Frequency & $\mathrm{F}_{\mathrm{s}}=10$ to $1000 \mathrm{kHz}$ \\
\hline Maximum Reference Relative Ripple & $\delta_{\text {Ref max }}=1.0$ \\
\hline Line Frequency & $\mathrm{f}=50 \mathrm{~Hz}$ \\
\hline
\end{tabular}

Before starting this analysis, we will present a brief summary of the frequency modulation (FM) operation mode. In this operation mode the on time $t_{\text {on }}$ of the switch transistor is constant [4]. The off time changes continuously. After the on time $t_{o n}$, the switch is turned off and stays so, until the diode current $i_{d}(t)$ becomes zero, when another cycle starts. In other words when $i_{d}(t)$ becomes zero the switch is turned on. 
The converter operates in the transition point between the continuous and discontinuous inductor current.

The use of the FM approach as described by [4] is justified because provides an effective reduction in the conducted EMI $\mathrm{DM}$ for the minimal SF values lower than $150 \mathrm{kHz}$ as described by [2]. As an additional advantages the control circuit that implement the FM approach is quite simple as described by [4]. Unfortunately the use of the FM approach with $t_{\text {on }}$ constant cannot provides unitary power factor (PF), except to the Boost converter. However quite ideal results are available.

When the converters are working in DCM it is common to use the $\mathrm{K}$ constant to design them, where $\mathrm{K}$ is defined as following:

$$
K=\frac{2 L}{R T}
$$

being $\mathrm{L}$ the converter inductance or the converter equivalent inductance, $\mathrm{R}$ is the full load resistance and $\mathrm{T}$ is the period of the SF, if we also use $\mathrm{T}$ equal to the period of the minimal SF $\left(\mathrm{T}_{\max }\right)$ we can also use the $\mathrm{K}$ constant to design the converter inductor in FM mode.

There is a critical value to the $\mathrm{K}$ constant $\left(\mathrm{K}_{\text {cri }}\right)$ which guarantee that the converter will work in DCM. Therefore, if one knows the $\mathrm{K}_{\text {cri }}$ it is possible to determine the $\mathrm{L}$ value, which allows an operating in DCM for all values of the input voltage $v_{e}(\mathrm{t})$. However, the converter could be designed to work with $\mathrm{K}$ values lower than $\mathrm{K}_{\text {cri }}$ in order to know the conducted EMI DM. For these cases, we also will present the design curves for $\mathrm{K}$ values lower than $\mathrm{K}_{\text {cri }}$.

\section{GAIN EQUATIONS}

To determine the conducted EMI differential mode $\mathrm{V}_{\text {noise }}$ in $\mathrm{dB} / \mu \mathrm{V}$ for a given converter according to the standard CISPR 16 [3], which peak input voltage and power are $V_{g \text { nom }}$ and $\mathrm{P}_{\text {nom }}$ respectively, we need to take into account the following equation:

$V_{\text {noise }}=\rho i_{\text {noise }} Z_{\text {LISN }}$

where $Z_{\text {LISN }}$ is the impedance of the Line Impedance Stabilisation Network (LISN), $\mathrm{i}_{\text {noise }}$ is the EMI differential mode current and $\rho$ is a function that represents the characteristics of the CISPR 16 measurement apparatus.

The conducted EMI DM noise in a converter with proportional waveforms that means, same topology and operation mode, and the characteristics shown in table 1 (reference converter), would be:

$V_{\text {noise }_{\text {Ref }}}=\rho i_{\text {noise }_{\text {Ref }}} Z_{\text {LISN }}$

From these equations we can obtain:

$V_{\text {noise }}=\frac{i_{\text {noise }}}{i_{\text {noise } \text { Ref }}} V_{\text {noise Ref }}$

But due to the fact that both converters have proportional waveforms, we can write:

$\frac{i_{\text {noise }}}{P_{\text {nom }} / V_{g_{\text {nom }}}}=\frac{i_{\text {noise } e_{\text {Ref }}}}{P_{\text {Ref }} / V_{g_{\text {Ref }}}}$
$V_{\text {noise }}=\frac{P_{\text {nom }} V_{g_{\text {Ref }}}}{P_{\text {Ref }} V_{g_{\text {nom }}}} V_{\text {noise } \text { Ref }}$

being $\mathrm{V}_{\mathrm{g} \text { Ref }}$ and $\mathrm{P}_{\text {Ref }}$ the peak input voltage and power shown in Table I. This equation can be re-written as follows:

$V_{\text {noise }}=\gamma V_{\text {noise }_{\text {Ref }}}$

where $\gamma=\mathrm{P}_{\text {nom }} \mathrm{V}_{\mathrm{g} \text { Ref }} /\left(\mathrm{P}_{\text {Ref }} \mathrm{V}_{\mathrm{g} \text { nom }}\right)$ is a scale constant. Expression (6) can be written in $\mathrm{dB} / \mu \mathrm{V}$ as in equation (7).

$V_{\text {noise }}(d B / \mu V)=20 \log \gamma+V_{\text {noise }}(d B / \mu V)$

Note that $V_{\text {noise }}$ Ref $(d B / \mu V)$ is the value obtained from the EMI design curves.

The conducted EMI DM generated by Boost converter in CCM and Sepic and Cuk converters in CCM, DCM and FM is proportional to the relative ripple then the equation (7) can be re-written in order to reflect this fact. The maximum relative ripple of the input current $\left(\delta_{\max }\right)$ is defined as follow:

$\delta_{\max }=\left[\frac{\Delta I_{L}}{I_{L_{\text {average }}}}\right]_{\text {maximum }}$

being, $\Delta \mathrm{I}_{\mathrm{L}}$ the input currents ripple $\Delta I_{L}=I_{L_{\max }}-I_{L_{\min }}$ and $\mathrm{I}_{\text {Laverage }}$ the average input current. Therefore the conducted EMI DM for this case can be expressed as in equation (10).

$V_{\text {noise }}(d B / \mu V)=20 \log \frac{\delta_{\max }}{\delta_{\max _{\text {Ref }}}}+20 \log \gamma+V_{\text {noise }_{\text {Ref }}}(d B / \mu V)$

Note that $\delta_{\max \text { ref }}$ was defined as being unitary.

The conducted EMI DM generated by the others converters in CCM is quite independent of the $\delta_{\max }$ value. Therefore, the equation (10) is not effective for this converters.

\section{BOOST CONVERTER IN DCM}

For the Boost converter in DCM with $\mathrm{d}$ constant, as proposed by Liu and Lin in [6], the EMI design curves are presented in Fig. 1. In this operation mode the converter also operates with constant SF. The $\mathrm{K}_{\text {cri }}$ value and the duty cycle are presented in the following equations:

$$
\begin{aligned}
& K_{c r i} \leq \frac{y(M)}{\pi} \frac{(M-1)^{2}}{M^{4}} \\
& d=M \sqrt{\frac{k \pi}{y(M)}}
\end{aligned}
$$

where $\mathrm{M}$ is the converter gain $\mathrm{M}=\mathrm{V} / \mathrm{V}_{\mathrm{g}}$ and $\mathrm{y}(\mathrm{M})$ is as follow:

$y(M)=\int_{0}^{\pi} \frac{M \operatorname{sen} \theta^{2}}{M-\operatorname{sen} \theta} d \theta$

From equations (3) and (4) we obtain: 


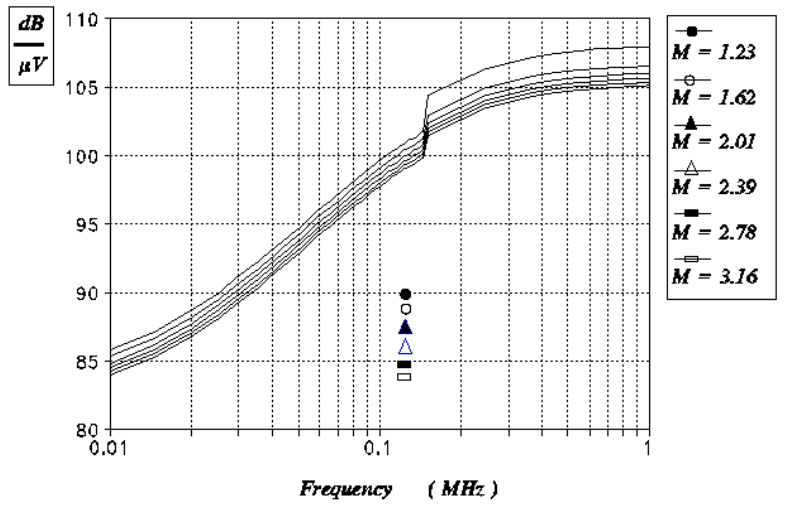

Fig. 1. EMI design curves for the Boost converter in DCM for K equal to Kcri.

\section{BOOST CONVERTER IN CCM}

When the Boost converter operates in Continuous Conduct Mode (CCM), the inductor value could be determinated as follow:

$$
L=\frac{V_{g}^{2} T}{2 P \delta_{\max }}
$$

In Fig. 2 we have the EMI design curves for this operation mode.

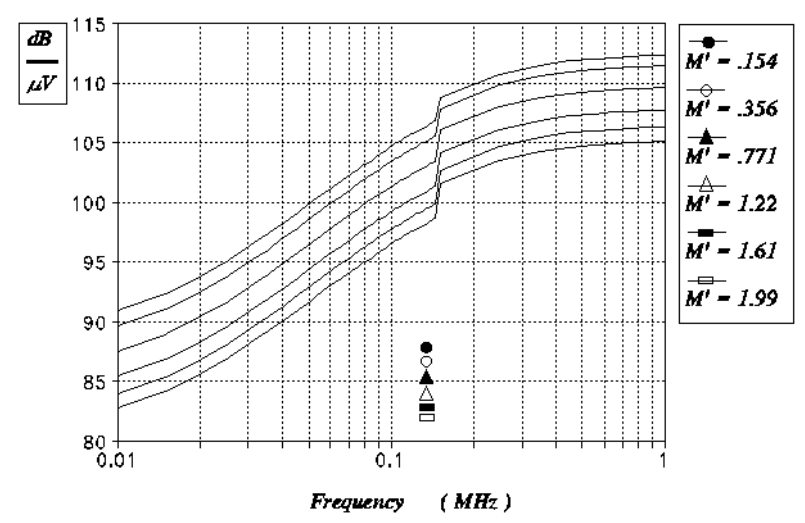

Fig. 2. EMI design curves for Boost converter in CCM for $\delta$ ref $=1$.

\section{BOOST CONVERTER IN FM}

In this operation mode the $\mathrm{K}_{\mathrm{cri}}, \mathrm{t}_{\mathrm{on}}$ and $\mathrm{T}$ values are as follow:

$$
\begin{aligned}
& K_{c r i}=\frac{(M-1)}{2 M^{3}} \\
& t_{o n}=T_{\max } \frac{(M-1)}{M} \\
& T=t_{\text {on }} \frac{M}{M-\operatorname{sen} \omega t}
\end{aligned}
$$

The EMI design curves for the FM mode are presented in Fig. 3.

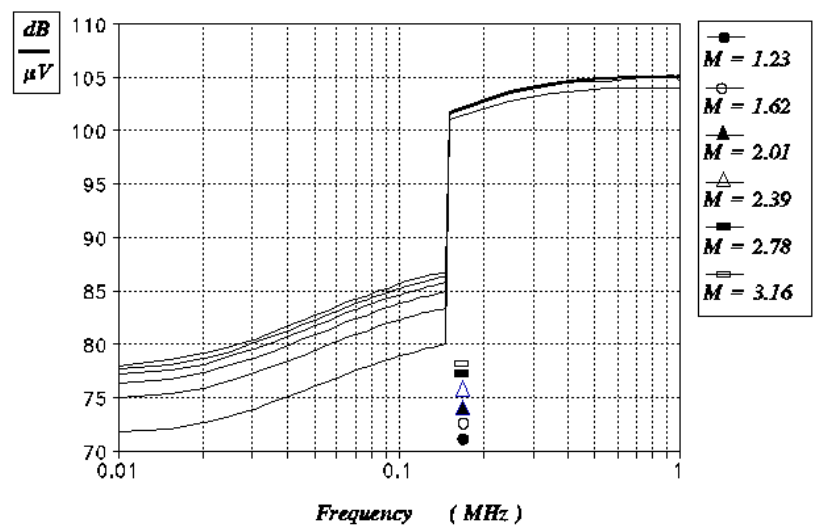

Fig. 3. EMI design curves for Boost converter in FM mode.

\section{BUCK-BOOST AND ZETA CONVERTERS IN CCM}

The EMI design curves which we will present for BuckBoost converters are also valid for the Zeta converter because it is easily demonstrated that both converters have the same input current if both have the same equivalent inductance $\mathrm{L}$ defined as:

$L=L_{1} / / \frac{L_{2}}{n_{T}^{2}}$

for the Zeta converter. The inductance L for both converters is presented in equation (19), being $\mathrm{n}_{\mathrm{T}}$ the turns ratio between primary and secondary, and $\mathrm{M}^{\prime}=\mathrm{M} / \mathrm{n}_{\mathrm{T}}$. Of course, the EMI design curves are also valid to the Flyback converter.

$L=\frac{R T}{2} \frac{1}{n_{T}^{2} M^{\prime 2} \delta_{\max }}$

In Fig. 4 we have the EMI design curves for this situation.

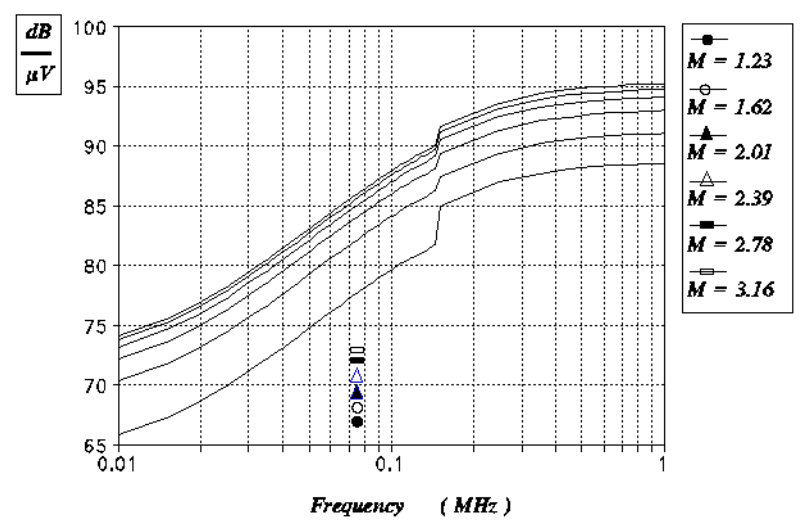

Fig. 4. EMI design curves for Buck-Boost, Flyback and Zeta converters in $\mathrm{CCM}$ with $\delta \max =1.0$.

\section{BUCK-BOOST AND ZETA CONVERTERS IN DCM}

When the Buck-Boost converter works in DCM, the critical value of the $\mathrm{K}\left(\mathrm{K}_{\text {cri }}\right)$ and the duty cycle $\mathrm{d}$ are given in equations (20) and (21) respectively. 


$$
\begin{aligned}
& K_{c r i} \leq \frac{1}{2 n_{T}^{2}\left(M^{\prime}+1\right)^{2}} \\
& d=\sqrt{2 K} n_{T} M^{\prime}
\end{aligned}
$$

For this case the EMI design curves are represented in Fig.5.

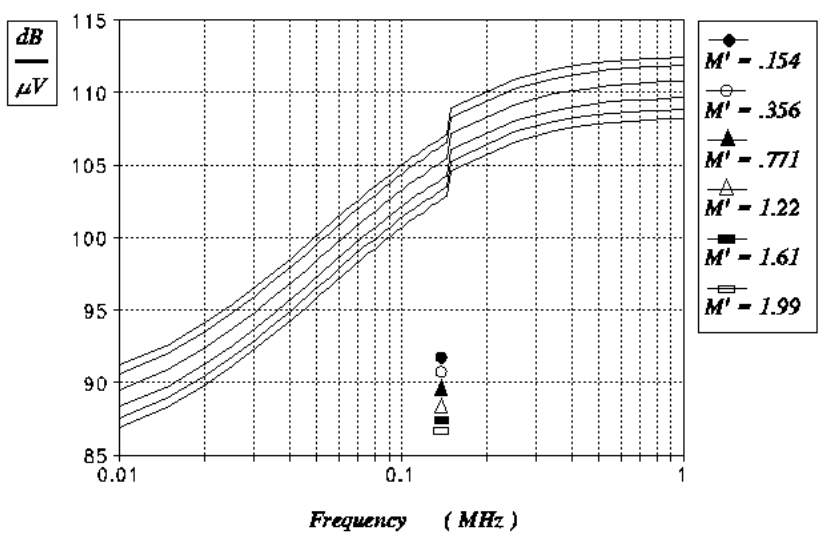

Fig. 5. EMI design curves for Buck-Boost, Flyback and Zeta converters in DCM for $\mathrm{K}=$ Kcri.

\section{BUCK-BOOST AND ZETA CONVERTERS IN FM}

For Buck-Boost and Zeta converters in FM, the $\mathrm{K}_{\text {cri, }}, \mathrm{t}_{\text {on }}$ and $\mathrm{T}$ values are shown in the equations (22) to (24).

$$
\begin{aligned}
& K_{c r i}=\frac{\Gamma\left(M^{\prime}\right)}{\pi n_{T}^{2}\left(M^{\prime}+1\right)} \\
& t_{o n}=T_{m} x \frac{M^{\prime}}{M^{\prime}+1} \\
& T=t_{o n} \frac{M^{\prime}+|\operatorname{sen} \omega t|}{M^{\prime}}
\end{aligned}
$$

being $\Gamma\left(M^{\prime}\right)$ :

$\Gamma\left(M^{\prime}\right)=\int_{0}^{\pi} \frac{\operatorname{sen}^{2} \theta}{M^{\prime}+\operatorname{sen} \theta} d \theta$

The EMI design curves to the Buck-Boost, Flyback and Zeta converters in FM mode are presented in Fig. 6.

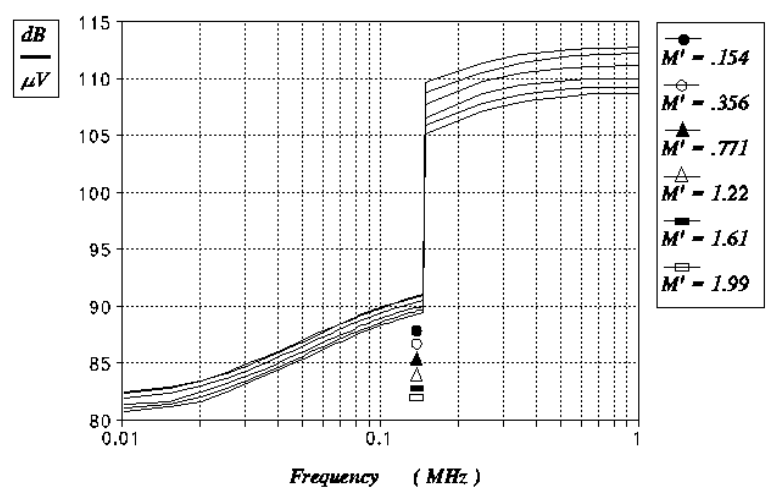

Fig. 6. EMI design curves for the Buck-Boost, Flyback and Zeta converters in FM mode.

\section{SEPIC AND CUK CONVERTERS IN CCM}

As in the case of the Boost converter in CCM the Sepic and Cuk converters in all operation modes are dependent of the $\delta_{\max }$ in accordance with equation (19). The inductors $\mathrm{L}_{1}$ and the equivalent inductor $\mathrm{L}$ are obtained in accordance with the following equations:

$$
\begin{aligned}
& L_{1}=\frac{R T}{2} \frac{1}{n_{T}^{2} M^{\prime 2} \delta_{\max }} \\
& L=\frac{R T}{4 n_{T}^{2} M^{\prime 2}}
\end{aligned}
$$

being the equivalent inductor $\mathrm{L}=\mathrm{L}_{1} / / \mathrm{L}_{2}$ for the Sepic converter and $\mathrm{L}=\mathrm{L}_{1} / /\left(\mathrm{L}_{2} / \mathrm{n}_{\mathrm{T}}^{2}\right)$ for the Cuk converter. In Fig. 7 is shown the EMI design curves for these converters.

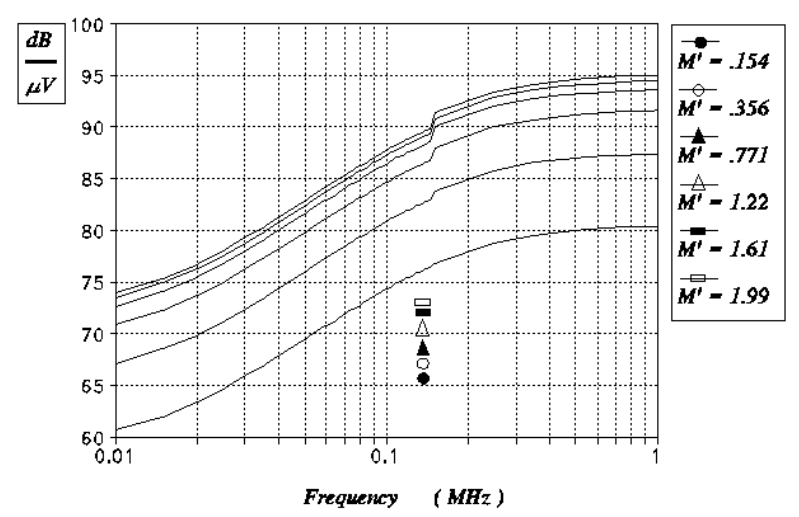

Fig. 7. EMI design curves for Sepic and Cuk converters in $\mathrm{CCM}$ with $\delta \max =1.0$.

\section{SEPIC AND CUK CONVERTERS IN DCM}

The $\mathrm{K}_{\text {cri }}$ for these converters is given by equation (20) and the duty cycle $\mathrm{d}$ for equation (21). Inductor $\mathrm{L}_{1}$ value is computed as follows:

$$
L_{1}=\frac{2 L}{d \delta_{\max }}
$$

The EMI design curves for these converters in DCM are represented, in Fig. 8. 


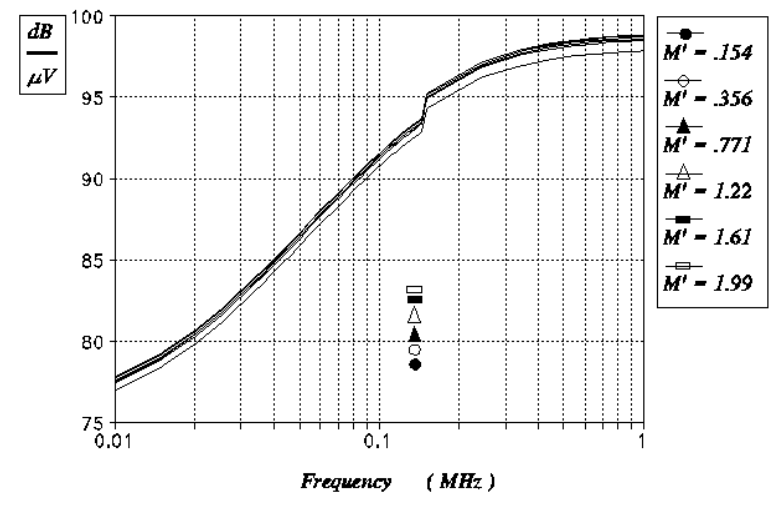

Fig. 8. EMI design curves for Sepic and Cuk converters in $\mathrm{DCM}$ for $\mathrm{K}=\mathrm{Kcri}$ and $\delta \mathrm{max}=1.0$.

\section{SEPIC AND CUK CONVERTERS IN FM}

For this operation mode, the $\mathrm{K}_{\text {cri }}$, the duty cycle $\mathrm{d}$ and the on time $t_{o n}$, can be obtained from the equations (22) to (24). Inductor $\mathrm{L}_{1}$ value is obtained as follows:

$$
L_{1}=\frac{2 L}{\delta_{\max }} \frac{M^{\prime}+1}{M^{\prime}}
$$

The EMI design curves for these converters in FM are represented, in Fig. 9.

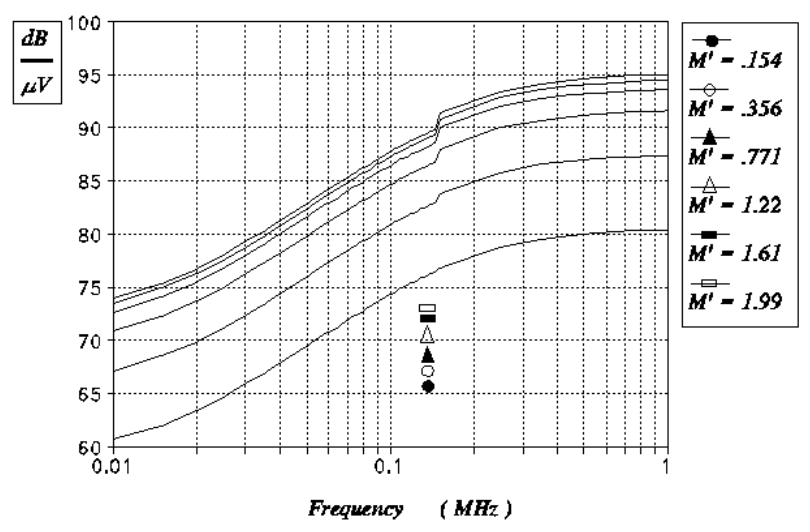

Fig. 9. EMI design curve for Sepic and Cuk converters in FM mode for $\delta \max =1.0$

\section{EMI DESIGN CURVES COMMENTS}

It is important to observe that at $\mathrm{F}_{\mathrm{s}}=150 \mathrm{kHz}$ the curves have a discontinuity. This discontinuity at $150 \mathrm{kHz}$ has its origin in the CISPR 16, which establishes changes in the measurement apparatus at this frequency. The most important change occurs in the bandwidth of the receiver that changes from $200 \mathrm{~Hz}$ to $9 \mathrm{kHz}$.

For the FM operation mode analysed here it is very important to observe that at $\mathrm{F}_{\mathrm{s} \text { min }}$ lower than $150 \mathrm{kHz}$ this approach presents an important reduction in the conducted
EMI DM in relation to DCM mode. On the other hand, when $F_{s \text { min }}$ is greater than $150 \mathrm{kHz}$ this effect is not significant.

\section{EMI FILTER DESIGN CONSIDERATIONS}

The design of a suitable EMI filter can be done according different approaches [7-9]. Usually a high-order filter is used to reduce inductance and capacitance values.

Ideally it could be considered that no harmonic components exist in the frequency range between the line and the switching frequencies. This fact would allow to center the filter resonance at a suitable frequency in order to guarantee the required attenuation. In this ideal situation the filter could be undamped.

In the Continuous Conduction Mode the input rectified voltage is usually used to create the current reference waveform. In this case the presence of instabilities in the filter output (converter side) can lead to severe converter malfunction [10].

As the input voltage waveform is not so important for the proper operation of the PFC in the Discontinuous Conduction Mode, some damping effect is necessary to avoid oscillations in the average input current produced by transient situations, like load or line changes.

According to the paper proposition, the filter will be designed considering only the differential mode EMI noise produced by the converter. For this filter type, not only the required attenuation but also other restrictions must be taken into account. For example, VDE standard specifies a maximum $\mathrm{x}$-type capacitance of $2.2 \mu \mathrm{F}$ [8] in order to limit the line current ( $50 / 60 \mathrm{~Hz}$ component) even at no load situation. The maximum capacitance should be used to minimise the inductance value.

Let us consider the damped second order filter topology shown in Fig. 10. This filter attenuates $40 \mathrm{~dB} / \mathrm{dec}$. For a given necessary attenuation, the cut-off frequency is given by:

$$
f_{c}=\frac{f_{x}}{10^{A_{1} / A_{2}}}
$$

where $f_{c}$ is the cut-off frequency, $f_{x}$ is the frequency in which the required attenuation $\left(A_{1}\right)$ is determined. $A_{2}$ is the filter characteristic attenuation.

The inductance value is given by:

$\mathrm{L}_{\mathrm{f}}=\frac{1}{4 \pi^{2} \mathrm{C}_{1} \mathrm{f}_{\mathrm{c}}^{2}}$

The maximum $\mathrm{C}_{1}+\mathrm{C}_{2}$ value is $2.2 \mu \mathrm{F}$ [8], and for a proper damping effect, $\mathrm{C}_{2}=10 \mathrm{C}_{1}$. The damping resistance can be calculated as:

$$
R_{d}=\sqrt{\frac{L_{f}}{C_{2}}}
$$




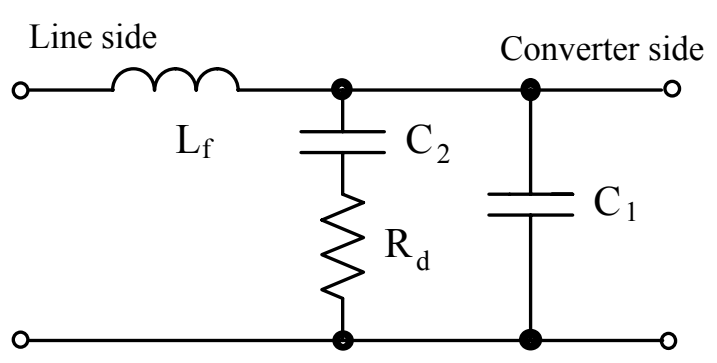

Fig. 10. EMI differential mode filter.

\section{DESIGN EXAMPLE}

The standard IEC CISPR 11 [11] determines limits for conducted noise for industrial, scientific and medical equipment (ISM). The limit for mains terminal disturbance voltage in the frequency band $150 \mathrm{kHz}$ to $500 \mathrm{kHz}$ is 66 $\mathrm{dB} / \mu \mathrm{V}$ (average level), measured according to CISPR 16.

Let us consider a Boost PFC, in DCM, and the 102 $\mathrm{dB} / \mu \mathrm{V}$ predicted EMI level shown in Fig. 1. The required filter attenuation is $36 \mathrm{~dB} / \mu \mathrm{V}$. To have this value at 150 $\mathrm{kHz}$, a second-order filter must have a cut-off frequency at $18.9 \mathrm{kHz}$ (equation (30)). Adopting $\mathrm{C}_{1}=220 \mathrm{nF}$ and $\mathrm{C}_{2}=2$ $\mu \mathrm{F}$, the inductance (equation (31)) and damping resistance (equation (32)) are, respectively, $322 \mu \mathrm{H}$ and $38 \Omega$. Fig. 11 shows the filter frequency response, given the $36 \mathrm{~dB}$ attenuation at $150 \mathrm{kHz}$.

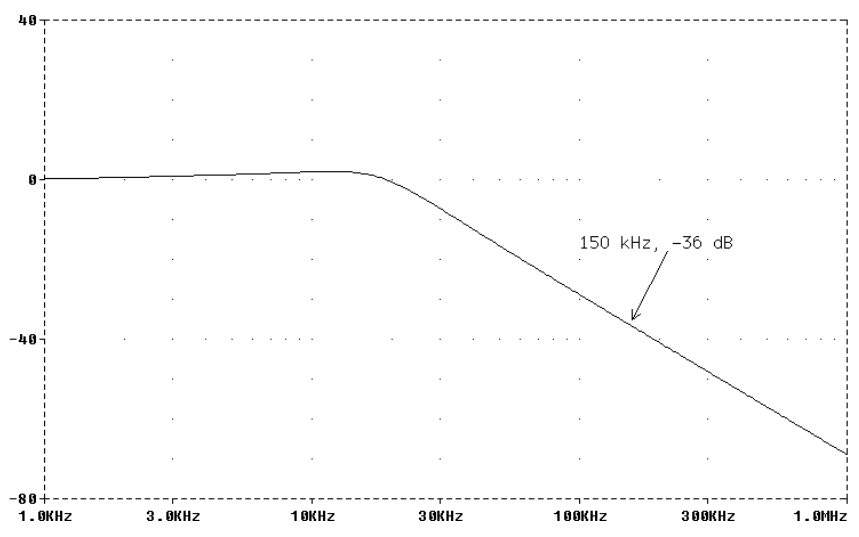

Fig. 11. EMI filter attenuation.

\section{CONCLUSIONS}

The proposed method for determination and reduction of PFC conducted EMI DM presented here can be an useful tool to help SMPS designers. This tool allows us to easily predict the amplitude of the first harmonic in $\mathrm{dB} / \mu \mathrm{V}$ in accordance with the CISPR 16 and to design the EMI filter. In this way we can design the filters without needing to make a prototype or make complex simulations. This method can be a contribution to the reduction of the product development time.

The analysis that we have developed in this paper is not a full description of the harmonics. But this simplification does not represent a big problem, because the design of the filter is generally made for the first harmonic. In the majority of cases the filter that eliminates the harmonics of low order $\left(\mathrm{F}_{\mathrm{s}}\right)$ also eliminates the harmonics of high order.

We must avoid design the converters in FM mode at $\mathrm{F}_{\mathrm{s} \text { min }}$ around $150 \mathrm{kHz}$. Minimal SF around $100 \mathrm{kHz}$ are preferred.

The presented curves are also useful at $\mathrm{f}=60 \mathrm{~Hz}$.

From the analysis we can conclude that the FM operation mode is an interesting solution in order to reduce the conducted EMI with simple control circuits. Unfortunately this solution is not effective for switching frequencies in the proximity and higher than $150 \mathrm{kHz}$.

The curves presented here are similar to those presented by Albach [4], but in this paper we present the curves as a function of normalised parameters $M$ and $\delta$. These curves associated with the gain equations permit us to obtain the conducted EMI DM (first harmonic) for a large range of converter specifications.

\section{REFERENCES}

1. Hewlett Packard. EMC In The European Environment Seminar. 1992.

2. F. S. Dos Reis, J. Sebastián, J. Uceda, 1994, PESC'94, $1117-1126$.

3. CISPR 16 - Specification for Radio Interference Measuring Apparatus and Measurement Methods, second edition 1987.

4. Albach, M. 1986. PESC'86, 203 - 212.

5. D.S.L. Simonetti, J. Sebastián, F.S. Dos Reis and J. Uceda. 1992. IECON 92, 283 - 288.

6. K. H. Liu and Y. L. Lin, 1989, PESC'89, 825 - 829.

7. V. Vlatkovic, D. Borojevic and F. C. Lee: "Input Filter

Design for Power Factor Correction Circuits”, 1993, IECON'93, 954-958

8. Y. F. Zhang, L. Yang and C. Q. Lee: "Optimal Design of Integrated EMI Filter", 1995, APEC'95, 274-280

9. M. V. Ataide and J. A. Pomilio: "Single-Phase Shunt Active Filter: a Design Procedure Considering harmonics and EMI Standards", 1997 ISIE'97, pp. 422-427.

10. G. Spiazzi and J. A. Pomilio: "Interaction between EMI Filter and Power Factor Preregulators with Average Current Control: Analysis and Design Considerations", 1999,

APEC'99.

11. CISPR 11 - Limits and methods of measurement of electromagnetic disturbance characteristics of industrial, scientific and medical (ISM) radio-frequency equipment., $2^{\text {nd }}$ edition, 1990. 